\title{
Comparative Analysis of Myocardial Protection with HTK Solution and Hypothermic Hyperkalemic Blood Solution in the Correction of Acyanogenic Congenital Cardiopathies - A Randomized Study
}

Acrisio Sales Valente1,2, MD; Gustavo Porto Lustosa², MD; Lia Alves Martins Mota², MD; Adriano Lima' ${ }^{1}$, MD; Fernando Antônio de Mesquita ${ }^{1}$, MD; Aloísio Gondim¹, MD; Fábio Alércio Rodrigues ${ }^{1}$, MD; Ronald Guedes Pompeu $^{3}$, MD; Klébia Castelo Branco ${ }^{3}$, MD

\section{Abstract}

Objective: The goal of the present study was to compare the myocardial protection obtained with histidine-tryptophanketoglutarate (HTK) cardioplegic solution (Custodiol ${ }^{\circledR}$ ) and with intermittent hypothermic blood solution.

Methods: Two homogenous groups of 25 children with acyanotic congenital heart disease who underwent total correction with mean aortic clamping time of 60 minutes were evaluated in this randomized study. Troponin and creatine kinaseMB curves, vasoactive-inotropic score, and left ventricular function were obtained by echocardiogram in each group. The values were correlated and presented through graphs and tables after adequate statistical treatment.
Results: It was observed that values of all the studied variables varied over time, but there was no difference between the groups.

Conclusion: We conclude that in patients with acyanotic congenital cardiopathies submitted to total surgical correction, mean aortic clamping time around one hour, and cardiopulmonary bypass with moderate hypothermia, the HTK crystalloid cardioplegic solution offers the same myocardial protection as the cold-blood hyperkalemic cardioplegic solution analyzed, according to the variables considered in our study model.

Keywords: Congenital Heart Disease, CHD. Cardiopulmonary Bypass, CPB (Incl Set-Ups, Equipment, Surface Coatings, Etc.), Pediatric. Myocardial Protection/Cardioplegia. Myocardial Injury (Incl Blunt, Penetrating, latrogenic).

Abbreviations, acronyms \& symbols

$\begin{array}{ll}\text { ANOVA } & =\text { Analysis of variance } \\ \text { ASD } & =\text { Atrial septal defect } \\ \text { AVC } & =\text { Atrioventricular canal } \\ \text { CAVC } & =\text { Complete atrioventricular canal } \\ \text { CK-MB } & =\text { Creatine kinase-MB } \\ \text { CPB } & =\text { Cardiopulmonary bypass } \\ \text { d-TGA } & =\text { dextro-transposition of the great arteries } \\ \text { DORV } & =\text { Double outlet right ventricle } \\ \text { EF } & =\text { Ejection fraction } \\ \text { HHB } & =\text { Hypothermic hyperkalemic blood } \\ \text { HTK } & =\text { Histidine-tryptophan-ketoglutarate } \\ \text { ICU } & =\text { Intensive care unit }\end{array}$

ICU
IPO
PD
$=$ Immediate postoperative
PDA
$1 P O$
$=$ Peritoneal dialysis
$=$ Patent ductus arteriosus
$16 \mathrm{PO}$
$=$ First postoperative
ReBEC
RS
SD
SIRS
TTE
VIS
VSD

'Department of Surgery, Hospital de Messejana Dr. Carlos Alberto Studart Gomes, Fortaleza, Ceará, Brazil.

${ }^{2}$ Centro Universitário Unichristus, Fortaleza, Ceará, Brazil.

${ }^{3}$ Department of Congenital Heart Disease, Hospital de Messejana Dr. Carlos Alberto Studart Gomes, Fortaleza, Ceará, Brazil.

This study was carried out at Hospital de Messejana Dr. Carlos Alberto Studart Gomes, Fortaleza, Ceará, Brazil.
Correspondence Address:

Acrisio Sales Valente

(iD https://orcid.org/0000-0003-2094-8109

Rua Alberto Feitosa Lima, 180 - Fortaleza, CE - Brazil

Zip code: 60810-018

E-mail: acrisiovalente@yahoo.com 


\section{INTRODUCTION}

The development of the cardiac surgery is directly related to the evolution of myocardial protection techniques, which have made possible complex and long surgeries with adequate preservation of the cardiac function. The already known benefits of hypothermia in reducing the myocardial metabolic demand were associated with chemical cardioplegia, which is characterized by the administration of solutions in coronary arteries that can cause myocardial arrest, preserving the reserves of high-energy phosphate, reducing oxygen consumption, and offering oxygen and other substrates during aortic clamping. Initially proposed by Melrose ${ }^{[1]}$, in 1955, with a solution of $2.5 \%$ potassium citrate diluted in blood, this method was then abandoned because of the demonstration of myocardial injury caused by high concentrations of potassium ${ }^{[2]}$. However, it showed great improvement and acceptance in the 1970s, when researchers from Europe $\mathrm{e}^{[3,4]}$ and North America ${ }^{[5,6]}$ reintroduced the cardioplegic protection by infusing cold crystalloid solutions containing magnesium chloride and potassium chloride at lower concentrations than those from Melrose solution. In Brazil, Braile was one of the main responsibles for the implementation and development of chemical cardioplegia ${ }^{[7]}$.

The myocardial protection techniques remain a reason for great discussions. Questions about the best route of administration (anterograde, retrograde, or both together), ideal temperature (hypothermic, normothermic, or heated), frequency of administration (intermittent or continuous), and its various formulations diluted in blood or crystalloid solutions generate recurrent debates. Solutions diluted in blood are the preference of many surgeons because they have a more physiological composition, with natural buffers and oxygen-carrying capacity. However, crystalloid solutions remain the choice of some groups. One of the most used formulations is that developed by Bretschneider, in 1970, also known as histidine-tryptophanketoglutarate (HTK) solution (Custodiol $\left.{ }^{\circledR}\right)$. This solution is widely used for organ preservation in transplants and, in general, it requires a single administration ${ }^{[8,9]}$.

Initially idealized for cardiac surgeries in adults, cardioplegic solutions were soon adapted for pediatric cardiac surgeries ${ }^{[10]}$. However, the child's heart behaves differently from the adult's heart in relation to ischemia, since there are structural, functional, and metabolic differences, being the child's heart more vulnerable to myocardial injury. This is due not only to the associated malformations, but also to the organ immaturity ${ }^{[11-13]}$. In the Pediatric Heart Surgery Service, at the Hospital do Coração Dr. Carlos Alberto Studart Gomes (Fortaleza, Ceará, Brazil), about 450 pediatric cardiac surgeries are performed per year, most of them using cardiopulmonary bypass (CPB) with aortic clamping and administration of cardioplegic solution. The authors are responsible for approximately half of these surgeries. Initially, a hypothermic blood solution formulation with potassium addition was administered predominantly to the aortic root every 30 minutes. With the advent of the HTK crystalloid hypothermic solution in heart transplants in our hospital, some groups extended its use, due to the practicality of a single administration, to other cardiac surgeries in adults and children.

The objective of this study was to compare the efficacy of two cardioplegic solutions used for myocardial protection in two homogenous groups of children submitted to surgical correction of congenital heart diseases: HTK solution and hypothermic hyperkalemic blood (HHB) solution.

\section{METHODS}

This is a longitudinal, prospective, clinical, randomized, and double-blind trial. Fifty children consecutively operated on from November 2012 to June 2014 were evaluated by the same surgical team. All of them were carriers of acyanotic congenital cardiopathies, which were corrected with CPB and aortic clamping. Surgeries for correction of atrial septal defect (ASD) exclusively, reoperations, and palliative and emergency surgeries were excluded. The children were randomized into two groups of 25 patients: in Group A, patients received the cold HTK solution (about $5^{\circ} \mathrm{C}$ ), administered as a single dose in the aortic root, for six minutes, with a minimum infusion of $30 \mathrm{~mL} / \mathrm{kg}$. In Group B, patients received the HHB solution at a concentration of $25 \mathrm{mEq} / \mathrm{L}$, administered at the root of the aorta with a syringe, at a temperature of $20^{\circ} \mathrm{C}$ (priming temperature), every 30 minutes, in a volume of $20 \mathrm{~mL} / \mathrm{kg}$ in induction and 10 $\mathrm{mL} / \mathrm{kg}$ in maintenance. The 50 numbers were randomized by the Epi Info software version 3.5.1 and placed in separate and sealed envelopes. These envelopes were removed and opened randomly and immediately prior to the application of the solution. In defining the sample size, we considered the number of patients with this profile operated by the specific team during the year.

Researchers who performed the data collection in the medical record and specific protocol did not know which type of solution was used; only the surgeon in charge had access to this information (he knew the randomization seal).

The parameters evaluated in this study were: age (months), weight (kilogram), gender, type of cardiopathy, duration of surgery, CPB, and aortic clamping time (minutes); for each of these variables the mean was calculated and, later, a correlation between the two groups was performed. The evaluation of myocardial damage was made through three variables: dosage of cardiac enzymes, troponin, and creatine kinase-MB (CK-MB). Enzymes were collected preoperatively at the end of surgery and six, 12, 18,24, and 48 hours after surgery. The type and number of vasoactive drugs used every two hours were analyzed in the first 36 hours after surgery. From these vasoactive drug data, the vasoactive-inotropic score (VIS) was calculated using the formula presented in Table $1^{[14]}$.

Table 1. Vasoactive-inotropic score (VIS) formula.

\section{VIS $=($ dopamine $[\mathrm{mcg} / \mathrm{kg} / \mathrm{min}])+($ dobutamine $[\mathrm{mcg} / \mathrm{kg} / \mathrm{min}])$}

$+(10 \times$ milrinone $[\mathrm{mcg} / \mathrm{kg} / \mathrm{min}])$

$+(100 \times$ adrenaline $[\mathrm{mcg} / \mathrm{kg} / \mathrm{min}])$

$+(100 \times$ norepinephrine $[\mathrm{mcg} / \mathrm{kg} / \mathrm{min}])$ 
In addition, children underwent transthoracic echocardiography (TTE) in the preoperative period, immediate postoperative period, and between 24-48 hours after surgery, in order to determine the left ventricular function by the percentage of shortening $(\triangle D)$. Data were collected from surgical reports and a specific protocol created for the study. In the period of the study, the solutions' efficacy in myocardial protection was compared through the correlation of the estimated marginal means of the previously mentioned parameters, arranged in charts and table.

Categorical quantitative results were presented as percentages and counts, and the numerical results were presented as measures of central tendency. KolmogorovSmirnov normality tests were performed for numerical variables. For non-serial measurements, the chi-square test was used for categorical data and the analysis of variance (ANOVA) was used for numerical data. General linear models were used with repeated measurements of the mixed ANOVA type to evaluate serial measurements. Comparisons with $P$-value up to 0.05 were considered significant. Data were tabulated and analyzed by SPSS software (v. 23, SPSS, Inc.), for analysis and evaluation of data obtained in the collection.

The study followed the ethical principles of research involving human beings in the Resolution 466/12 of the National Health
Council, respecting the fundamental principles of autonomy, beneficence, non-maleficence, justice, and equity. It was approved by the Ethics and Research Committee of the Hospital do Coração Dr. Carlos Alberto Studart Gomes, protocol number $892 / 12$. And it was registered in the Brazilian Registry of Clinical Trials (ReBEC), Registration Number RBR-9wqbx9.

\section{RESULTS}

The majority of the patients were female (62\%) and had ventricular septal defect (VSD) as the main heart disease (78\%), associated or not with other lesions. A total of six (12\%) patients required cardiac defibrillation/cardioversion after CPB, one (2\%) required peritoneal dialysis (PD), and one (2\%) died. There was no statistical difference between the groups for any of these variables (Table 2).

Table 3 shows the range sampling (RS) distribution, means, and standard deviation (SD) of age, weight and time of CPB, and surgery and aortic clamping according to the groups. There was no statistical difference between the groups for any of these variables (Table 3).

Regarding the behavior of the troponin, CK-MB, VIS, and TTE variables, all of them varied significantly in time (all $P 1<0.001$ ),

Table 2. Distribution of categorical variables according to the groups.

\begin{tabular}{|c|c|c|c|c|}
\hline \multirow{2}{*}{ Variables } & \multicolumn{2}{|c|}{ Solution - N (\%) } & \multirow{2}{*}{$\begin{array}{l}\text { Total } \\
\text { N (\%) }\end{array}$} & \multirow{2}{*}{$P$} \\
\hline & A & B & & \\
\hline \multicolumn{5}{|l|}{ Sex } \\
\hline Female & $16(64)$ & $15(60)$ & $31(62)$ & 0.771 \\
\hline Male & $9(36)$ & $10(40)$ & $19(38)$ & \\
\hline \multicolumn{5}{|l|}{ Main cardiopathy } \\
\hline VSD & $18(72)$ & $22(88)$ & $40(78)$ & 0.157 \\
\hline CAVC & $5(20)$ & $2(8)$ & $7(14)$ & 0.221 \\
\hline Partial AVC & - & $1(4)$ & $1(2)$ & 0.312 \\
\hline DORV with infundibular and valvular pulmonary stenosis & $1(4)$ & - & $1(2)$ & 0.312 \\
\hline Subvalvar aortic stenosis & $1(4)$ & $1(4)$ & $2(4)$ & 0.952 \\
\hline "Pink tetralogy" & $2(8)$ & - & $1(2)$ & 0.132 \\
\hline \multicolumn{5}{|l|}{ Cardioversion } \\
\hline No & $21(84)$ & $23(92)$ & $44(88)$ & 0.384 \\
\hline Yes & $4(16)$ & $2(8)$ & $6(12)$ & \\
\hline \multicolumn{5}{|l|}{ PD } \\
\hline No & $25(100)$ & $24(96)$ & $49(98)$ & 0.312 \\
\hline Yes & - & $1(4.0)$ & $1(2)$ & \\
\hline \multicolumn{5}{|l|}{ Death } \\
\hline No & $25(100)$ & $24(96)$ & $49(98)$ & 0.312 \\
\hline Yes & - & $1(4)$ & $1(2)$ & \\
\hline
\end{tabular}

$\mathrm{AVC}=$ atrioventricular canal; $\mathrm{CAVC}=$ complete atrioventricular canal; DORV=double outlet right ventricle; $\mathrm{PD}=$ peritoneal dialysis; VSD=ventricular septal defect 
Table 3. Distribution of numerical variables according to the groups.

\begin{tabular}{l|c|c|c|c|c|c|c|}
\hline \multirow{2}{*}{ Variables } & \multicolumn{2}{|c|}{ Solution A } & \multicolumn{2}{c|}{ Solution B } & \multicolumn{3}{c}{ Total } \\
\cline { 2 - 8 } & RS & Mean (SD) & RS & Mean (SD) & RS & Mean (SD) & P \\
\hline Age (days) & $3-168$ & $28.5(41.65)$ & $2-108$ & $18.6(25.61)$ & $2-168$ & $23.5(34.58)$ & 0.501 \\
\hline Weight (kg) & $4-25$ & $11.2(11.51)$ & $3-25$ & $8.4(5.47)$ & $3-59$ & $9.8(9.03)$ & 0.632 \\
\hline CPB time (minutes) & $40-125$ & $80.3(22.25)$ & $42-135$ & $79.8(22.49)$ & $40-135$ & $80.0(22.14)$ & 0.816 \\
\hline Surgery time (minutes) & $110-270$ & $170.7(36.76)$ & $75-212$ & $164.0(31.77)$ & $75-275$ & $167.3(33.90)$ & 0.662 \\
\hline Clamping time (minutes) & $26-90$ & $57.8(20.46)$ & $20-90$ & $54.2(17.90)$ & $20-98$ & $56.1(19.12)$ & 0.640 \\
\hline
\end{tabular}

$\mathrm{RS}=$ range sampling; $\mathrm{CPB}=$ cardiopulmonary bypass; $\mathrm{SD}=$ standard deviation

but with no difference between the solutions $(P 2)$, as shown in the graphs of the estimated marginal means (Figures 1 to 4 ).

Table 4 presents the marginal means of troponin, CK-MB, VIS, and TTE between the groups at the different moments analyzed. For all variables, there was significant variation in time, but there was no interaction of time with the type of solution.

\section{DISCUSSION}

The importance of adequate myocardial protection for a good surgical result, especially in pediatric cardiac surgery, due to the greater susceptibility of the child's heart to ischemic damage, leads to a continuous search for the set of actions that results in a better preservation of the organ during the period of ischemia necessary for the correction of most congenital heart diseases. The type of coronary solution to be administered represents an important factor in this process. Previous studies have demonstrated the benefits of blood cardioplegic solutions

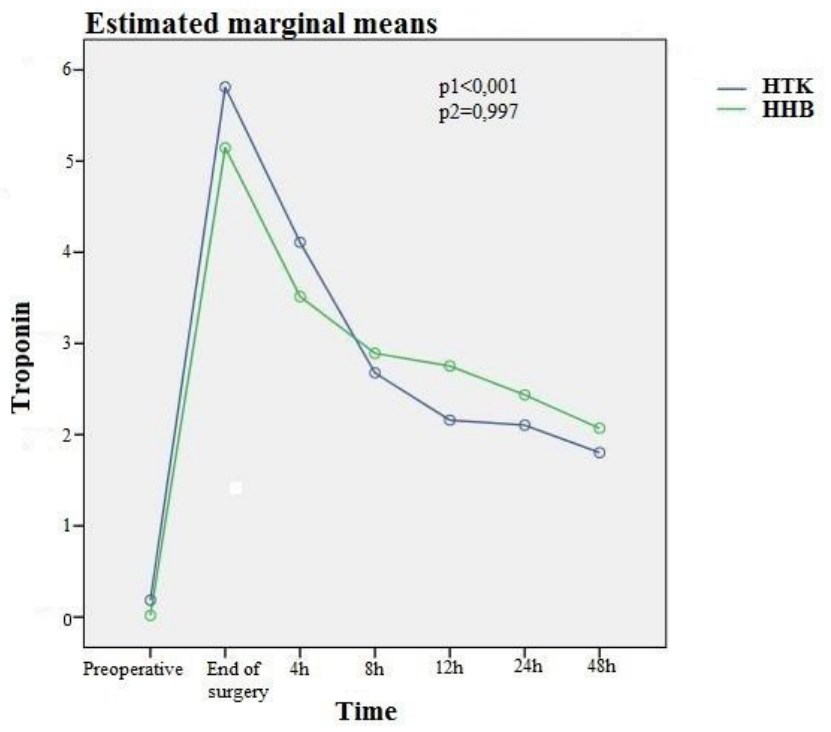

Fig. 1 - Variation of troponin in time (P1) and between groups (P2). HHB=hypothermic hyperkalemic blood; HTK=histidine-tryptophanketoglutarate in relation to cold crystalloid solutions, defined by better clinical evolution and lower postoperative troponin values ${ }^{[15-17]}$. All of this makes some sense, considering the expected more physiological properties of blood in relation to crystalloid solutions. However, several surgeons continue to use crystalloid solutions with good results. In our hospital, we have been using the St. Thomas' crystalloid solution for a long time in pediatric cardiac surgeries and heart transplants. Subsequently, we began to use, in pediatric surgeries, the intermittent HHB solution studied here, with good results. Finally, the HTK solution initially used for heart transplants have been standardized as the cardioplegic solution for pediatric congenital heart surgeries by pediatric surgeons of the transplant group. However, despite the apparently good results, the question remained whether this new solution would yield results better than or equal to the ones from the previously used solution, although this new one is more practical. Thus, the purpose of this study arose.

\section{Estimated marginal means}

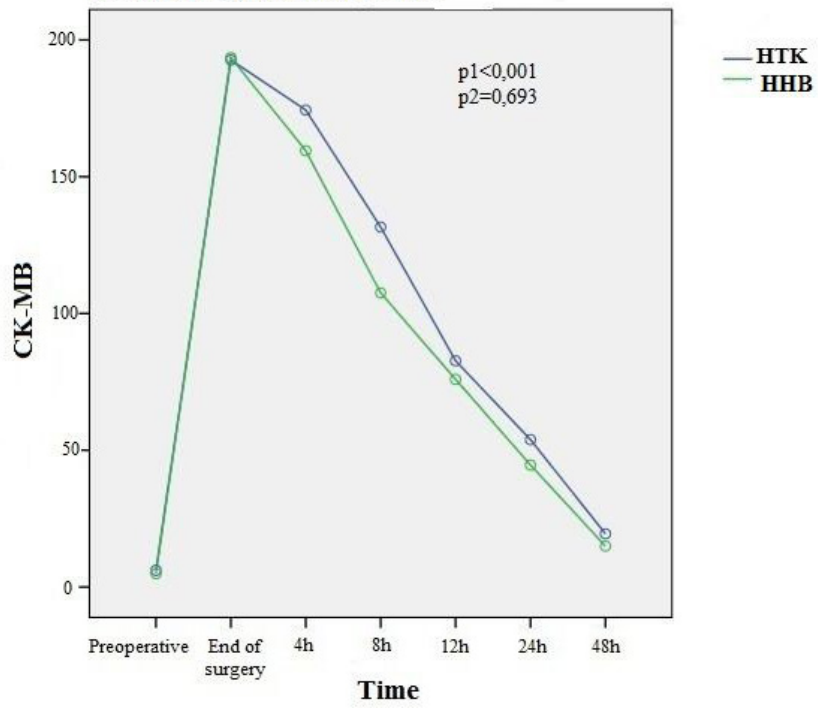

Fig. 2 - Variation of creatine kinase-MB (CK-MB) in time (P1) and between groups (P2).

$H H B=$ hypothermic hyperkalemic blood; HTK=histidine-tryptophanketoglutarate 


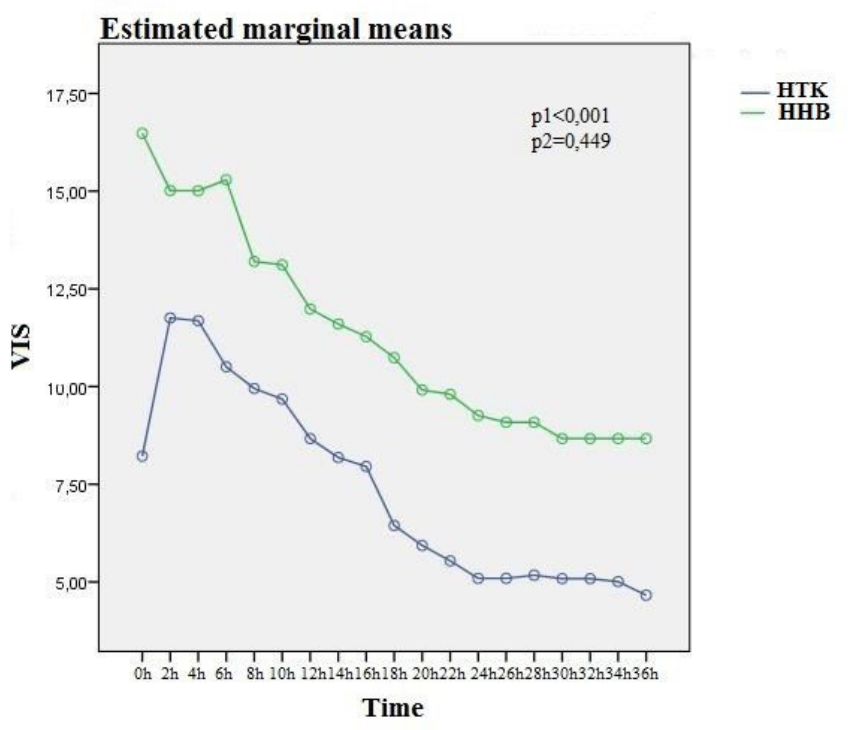

Fig. 3 - Variation of vasoactive-inotropic score (VIS) in time (P1) and between groups (P2).

HHB=hypothermic hyperkalemic blood; HTK=histidine-tryptophanketoglutarate

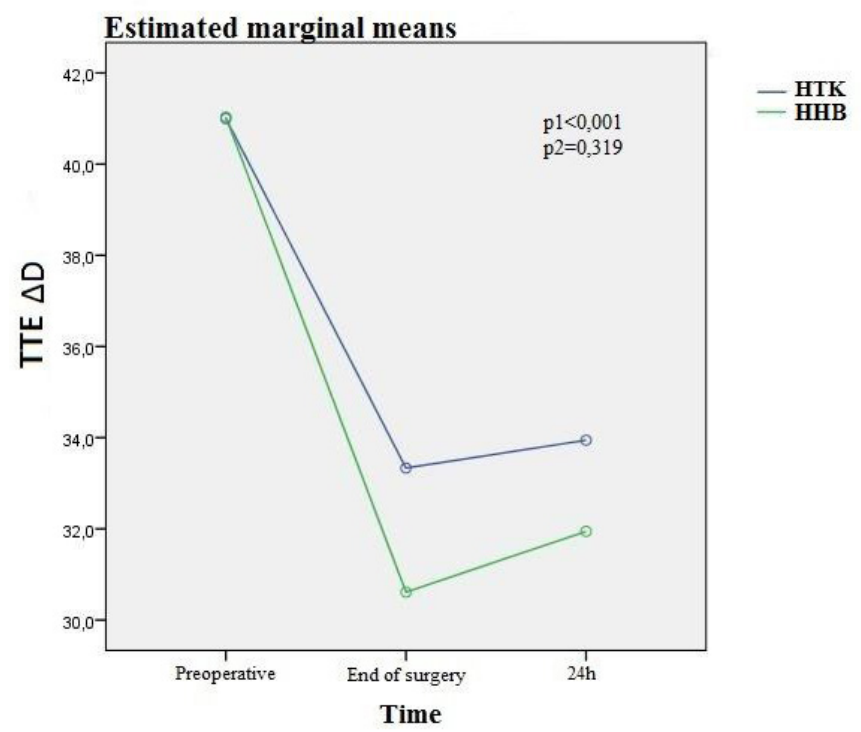

Fig. 4 - Variation of transthoracic echocardiography (TTE) in time (P1) and between groups (P2).

$H H B=$ hypothermic hyperkalemic blood; HTK=histidine-tryptophanketoglutarate

Regarding the sample choice, we are aware of the aggressions that the cardiopathy itself can cause to the myocardium. Cyanotic heart diseases, for example, may exert a bias, since different times of chronic hypoxia may characterize hearts more or less susceptible to myocardial damage, trans and postoperatively. Aiming to minimize these biases, we sought a more homogeneous study population and more predictable myocardial behavior in relation to surgical damage. Therefore, we selected only acyanotic congenital cardiopathies and elective procedures. These surgeries also present a more uniform course and, consequently, more similar surgical times. For the same reason, reoperations were excluded. Other studies with other subgroups of patients may be performed.

The studied group was, in fact, homogeneous, presenting similar distribution of sex, age, and weight. Duration of surgery, echocardiography, and aortic clamping time also did not present a statistically significant difference between the groups. On the latter, the general averages were 57.8 \pm 20.46 and 54.2 \pm 17.90 minutes for Groups A and B, respectively. Thus, we will assume that the results found in the present study may refer to surgeries in acyanotic cardiopathies with mean aortic clamping time around one hour.

Analyzing the results, the cardiac enzyme curves presented similar behavior among themselves. Both variables varied significantly over time, i.e., they increased significantly in relation to the preoperative values, but without difference between the groups, as shown in Figures 1 and 2 and in Table 4. Regarding troponin, specifically, there was an upper initial elevation in the group that received the HTK solution, although with no statistical difference. We may question whether it would not become significant if the " $n$ " were larger, characterizing a trend. In the CK-MB curve, however, these values were already very close. It is also known that it is the magnitude of the CK-MB values that correlates with the extent of the infarction, not the troponin values.

VIS is a predictor of the short-term evolution of children undergoing cardiac surgery. Davidson et al. ${ }^{[19]}$ concluded that a high VIS at 48 hours after pediatric cardiovascular surgery is related to prolonged mechanical ventilation and intensive care unit (ICU) stay. In our study, with respect to VIS curves, these also varied significantly over time, but with no interaction between time and type of solution. However, the VIS values of the group receiving $\mathrm{HHB}$ solution were initially higher than the ones of the HTK group and remained higher over time. It occurs that, in this group, we had two patients with special evolutions, needing more drugs and reaching VIS of 111 and 126. The first case was a total correction of complete atrioventricular canal (CAVC) in a 5-month-old infant with Down syndrome, which evolved with an important vasoplegic condition and pneumonia, requiring prolonged use of adrenaline. Its ventricular function in the immediate postoperative (IPO) and 1PO TTEs remained normal. The second case was 2-month-old and 3300-g child undergoing emergency surgery for heart failure. The preoperative TTE showed large VSD with ASD and patent ductus arteriosus (PDA). In the intraoperative period, multiple VSDs were detected, with a larger VSD and ASD and PDA being corrected. The TTE in IPO showed ejection fraction (EF) of $54 \%$ and $\triangle D$ of $25 \%$; in $1 P O$, those were $61 \%$ and $30 \%$, respectively. This child, however, progressed with severe systemic inflammatory response syndrome (SIRS), evolving to death in 16PO, the only death of the study. We chose to maintain these two cases in the study, considering that they were not able to significantly interfere with the behavior of the groups and through the description of the facts. Interestingly, the behavior of VIS was not accompanied by changes in cardiac enzyme values and ventricular function in TTE. 
Table 4. Values of the marginal means of troponin, CK-MB, VIS, and TTE between the groups at the different moments analyzed.

\begin{tabular}{|c|c|c|c|c|}
\hline \multirow{2}{*}{ Variables } & \multicolumn{4}{|c|}{ Group A/Group B } \\
\hline & Troponin & CK-MB & VIS & TTE \\
\hline Preoperative & $0.15 / 0.04$ & $5.44 / 8.91$ & - & $40.5 / 41.3$ \\
\hline End of surgery (0h) & $5.89 / 5.90$ & $191.28 / 206.73$ & $8.22 / 16.48$ & $33.6 / 31.4$ \\
\hline After 2 hours & - & - & $11.75 / 15.01$ & - \\
\hline After 4 hours & - & - & 11.68/15.01 & - \\
\hline After 6 hours & $3.99 / 3.87$ & $163.45 / 166.14$ & $10.51 / 15.29$ & - \\
\hline After 8 hours & - & - & $9.95 / 13.20$ & - \\
\hline After 10 hours & - & - & $9.68 / 13.11$ & - \\
\hline After 12 hours & $2.88 / 3.11$ & $123.18 / 108.42$ & $8.67 / 11.99$ & - \\
\hline After 14 hours & - & - & $8.18 / 11.60$ & - \\
\hline After 16 hours & - & - & $7.95 / 11.28$ & - \\
\hline After 18 hours & $2.21 / 2.69$ & $76.51 / 61.79$ & $6.44 / 10.74$ & - \\
\hline After 20 hours & - & - & $5.93 / 9.91$ & - \\
\hline After 22 hours & - & - & $5.54 / 9.80$ & - \\
\hline After 24 hours & $2.17 / 2.45$ & $55.33 / 44.10$ & $5.09 / 9.26$ & $34.9 / 34.4$ \\
\hline After 26 hours & - & - & $5.09 / 9.09$ & - \\
\hline After 28 hours & - & - & $5.17 / 9.09$ & - \\
\hline After 30 hours & - & - & $5.08 / 8.67$ & - \\
\hline After 32 hours & - & - & $5.08 / 8.67$ & - \\
\hline After 34 hours & - & - & $5.01 / 8.67$ & - \\
\hline After 36 hours & - & - & $4.66 / 8.64$ & - \\
\hline After 48 hours & $1.80 / 1.83$ & $17.91 / 12.39$ & - & - \\
\hline$P 2$ & 0.997 & 0.693 & 0.449 & 0.319 \\
\hline
\end{tabular}

$\mathrm{CK}-\mathrm{MB}=$ creatine kinase-MB; TTE=transthoracic echocardiography; $\mathrm{VIS}=$ vasoactive-inotropic score

Regarding the ventricular function, although we analyzed the $E F$ and $\triangle D$ (shortening), we chose the latter for graphic demonstration in our study. We emphasize that, as expected, both variables showed compatible variations. We observed that there was a variation over time with a reduction of $\Delta D$ in the first 24 hours in relation to the preoperative examination, followed by partial recovery in the next examination, and there was no statistically significant difference between the groups. In summary, the HTK group received fewer vasoactive drugs than the HHB group as well as presented less reduction of ventricular function, although without statistically significant difference. The HHB group (Group B), on the other hand, showed a lower initial peak of troponin and faster recovery of $C K-M B$, also with $P>0.05$, than the HTK group.

Some comparative studies have already been published on other cold crystalloid and intermittent heated blood solutions in pediatric cardiac surgery, showing better results with the latter solution (less release of troponin and clinical evolution) ${ }^{[15-17]}$. Evaluations of the HTK solution in relation to HHB solutions in adults have also been published with conflicting results and the intermittent $\mathrm{HHB}$ solution appeared to be superior to the single dose of HTK in left ventricular preservation after 60 minutes of aortic cross-clamping in a model with juvenile pigs $^{[20]}$. Our study is distinguished by the comparison of HTK solution and intermittent HHB solution among homogeneous groups of children with acyanotic congenital heart disease with mean ischemia time close to 60 minutes. Considering more severe patients and prolonged aortic clamping periods, a nonrandomized Chinese study, published in 2016, compared HTK and St. Thomas' solutions in a group of patients undergoing dextro-transposition of the great arteries (d-TGA) correction with VSD and major pulmonary hypertension. In this experiment, the HTK solution promoted better results than the St. Thomas' solution, which was translated into lower mortality and multiple organ failure ${ }^{[21]}$. Bojan et al. ${ }^{[22]}$ published in 2013 a French study comparing HTK solution and intermittent tepid blood solution in children undergoing Jatene surgery. In that study, the group that received HTK solution presented higher hemodilution, requiring 
higher ultrafiltration, higher release of troponin after surgery and higher mortality rate in 30 days, suggesting that the intermittent tepid blood solution was more effective. However, there was a large difference between the sample size of the groups (30 HTK and 188 blood solution cases) and the HTK group was formed by younger, smaller children than the ones in the intermittent tepid blood solution group, with a higher incidence of coronary anomalies. The time of ischemia varied between mean times of 72 to 124 minutes, depending on whether there were VSD or aortic arch conditions associated with d-TGA. After a risk-adjusted analysis excluding coronary anomalies, the postoperative troponin concentration remained higher in the HTK group than in the intermittent tepid blood solution group. Still in Jatene surgeries, Giordano et al.[23] published in 2015 a comparative analysis of HTK and cold blood solutions, showing similar results and being the HTK solution the choice for the group due to its simple use. The group receiving HTK, however, has been operated on in more recent years. In our study, changes in the troponin and CK-MB curves showed no difference. Both groups were composed of 25 patients and the variables characterized by these patients were similar. Our mean duration of ischemia was slightly less than 60 minutes, although some cases had longer times. The difficulty in forming similar groups for comparison was a recurrent aspect in such studies.

In 2001, Careaga et al. ${ }^{[18]}$ published a study comparing HTK and HHB solutions in two groups of 15 patients. It has shown benefits of the crystalloid solution in several aspects, including a lower incidence of arrhythmias and need for vasoactive drugs. The study, however, mixes heart diseases acquired in adults and pediatric surgeries, uses more than one blood solution, and evaluates variables that we judge difficult to control and, thus, were excluded from our study, as length of stay in ICU, which may suffer various influences such as infection, incidence of arrhythmias, and use of vasoactive drugs. Regarding this last variable, we find interesting the use of a score, as suggested by Butts et al[. ${ }^{[14]}$, for standardization. In 2002, Viana et al.[24] published in the European Journal of Cardio-Thoracic Surgery an Australian comparative experience between HTK solution and tepid blood solution. It was a retrospective study of 1900 adult patients who underwent surgery. Only $7 \%$ of these formed the group that used HTK. The groups were still very heterogeneous as in the presentation of risk factors and time of aortic clamping. In a first analysis, the benefits favored the blood solution, like lower mortality, incidence of arrhythmias, and time of mechanical ventilation, another variable of difficult consideration due to the biases that involve it. After a "propensity-matched analysis" with two groups of 71 patients, the results were similar for both solutions. Another interesting aspect would be the analysis of variations of the HTK solution. A Brazilian study, published in 2014, found no difference between the original composition and another one with glutamate replacing ketoglutarate in an experimental model with rats ${ }^{[25]}$.

In our study, two homogenous groups of 25 children with acyanotic congenital cardiopathies were prospectively analyzed for two types of cardioplegic solution used. The preoperative variables of the samples were similar. These characteristics classify the study as original and facilitate the correlation of data and interpretation of the results. New studies will be developed with the objective of comparing subgroups of congenital heart diseases and other methods of myocardial protection following the line of research of our group. The main limitation of the study is the size of the population analyzed. The right ventricular function has not been studied and should be an additional variable in future studies.

\section{CONCLUSION}

We conclude that, in patients with acyanotic congenital cardiopathies who underwent total surgical correction, mean aortic clamping time around one hour, and CPB with moderate hypothermia, the HTK crystalloid cardioplegic solution offers the same myocardial protection as the cold blood hyperkalemic cardioplegic solution, analyzed according to the variables considered in our study model.

\section{No financial support. \\ No conflict of interest.}

\section{Authors' roles \& responsibilities}

ASV Substantial contributions; final approval of the version to be published

GPL Substantial contributions; final approval of the version to be published

LAMM Substantial contributions; final approval of the version to be published

AL Agreement; final approval of the version to be published

FAM Agreement; final approval of the version to be published

AG Agreement; final approval of the version to be published

FAR Substantial contributions; final approval of the version to be published

RGP Substantial contributions; final approval of the version to be published

KCB Revising; final approval of the version to be published

\section{REFERENCES}

1. Melrose DG, Dreyer B, Bentall HH, et al. Elective cardiac arrest. Lancet. 1955;269(6879):21-2. doi:10.1016/S0140-6736(55)93381-X.

2. Helmsworth JA, Kaplan S, Clark LC Jr, McAdams AJ, Mattwes EC. Myocardial injury associated with asystole induced with potassium citrate. Ann Surg [Internet]. 1959 [cited 2019 Apr 27]; 149(2):2006. Available from: https://journals.Iww.com/annalsofsurgery/ Citation/1959/02000/Myocardial_Injury_Associated_with_Asystole_ Induced.5.aspx.

3. Hearse DJ, Stewart DA, Braimbridge MV, Chir B. Cellular protection during myocardial ischemia: the development and characterization of 
a procedure for the induction of reversible ischemic arrest. Circulation. 1976;54(2):193-202. doi:10.1161/01.CIR.54.2.193.

4. Bretschneider HJ, Hubner G, Knoll D, Lohi B, Nordbeck H, Spieckermann PG. Myocardial resistance and tolerance to ischemia: physiological and biochemical basis. J Cardiovasc Surg [Internet]. 1975[cited 2019 Apr 27];16(3):241-60. Available from: https://www.ncbi.nlm.nih.gov/ pubmed/239002.

5. Gay WA Jr, Ebert PA. Functional, metabolic, and morphologic effects of potassium-induced cardioplegia. Surgery [Internet]. 1973 [cited 2019 Apr 25];74(2):284-90. Available from: https://www.surgjournal.com/ article/0039-6060(73)90062-7/pdf.

6. Tyers GFD, Todd GJ, Neibaner IM, Manley NJ, Waldhausen JA. The mechanism of myocardial damage following potassium citrate (Melrose) cardioplegia. Surgery [Internet]. 1975 [cited 2019 Apr 25];78(1):45-53. Available from: https://www.surgjournal.com/ article/0039-6060(75)90187-7/pdf.

7. Braile DM. [How to do it: low volume backward normal thermic blood cardioplegia]. Rev Bras Cir Cardiovasc. 1992;7(3):221-9. doi:10.1590/ S0102-76381992000300010. Portuguese

8. Angeli E. The crystalloid cardioplegia: advantages with a word of caution. Ann Fr Anesth Reanim. 2011;30(Suppl 1):S17-9. doi:10.1016/S07507658(11)70003-X.

9. Arslan A, Sezgin A, Gultekin B, Ozkan S, Akay T, Uguz E, et al. Lowdose histidine-tryptophan-ketoglutarate solution for myocardial protection. Transplant Proc. 2005;37(7):3219-22. doi:10.1016/j. transproceed.2005.08.020

10. Imura H, Caputo M, Parry A, Pawade A, Angelini GD, Suleiman MS. Agedependent and hypoxia-related differences in myocardial protection during pediatric open heart surgery. Circulation. 2001;103(11):1551-6. doi:10.1161/01.CIR.103.11.1551.

11. Salerno PF, Jatene FB, Figueiredo PE, Bosisio IE, Jatene MB, Santos MA, et al. The behavior of troponin I and CKMB mass in children who underwent surgical correction of congenital heart malformations. Rev Bras Cir Cardiovasc. 2003;18(3):235-41. doi:10.1590/S0102-76382003000300008.

12. Kim JT, Park YH, Chang YE, Byon HJ, Kim HS, Kim CS, et al. The effect of cardioplegic solution-induced sodium concentration fluctuation on postoperative seizure in pediatric cardiac patients. Ann Thorac Surg. 2011;91(6):1943-8. doi:10.1016/j.athoracsur.2011.02.003.

13. Moore KL, Persaud TVN. Embriologia clínica. 8th ed. Rio de Janeiro: Elsevier; 2008. Chapter 13, Sistema Cardiovascular; p. 296-313.

14. Butts RJ, Scheurer MA, Atz AM, Zyblewski SC, Hulsey TC, Bradley SM, Graham EM. Comparison of maximum vasoactive inotropic score and low cardiac output syndrome as markers of early postoperative outcomes after neonatal cardiac surgery. Pediatr Cardiol. 2012;33(4):6338. doi:10.1007/s00246-012-0193-z.

15. Pouard P, Mauriat P, Ek F, Haydar A, Gioanni S, Laquay N, et al. Normothermic cardiopulmonary bypass and myocardial cardioplegic protection for neonatal arterial switch operation. Eur J Cardiothorac Surg. 2006;30(5):695-9. doi:10.1016/j.ejcts.2006.07.032.

16. Caputo M, Bays S, Rogers CA, Pawade A, Parry AJ, Suleiman S, Angelini GD. Randomized comparison between normothermic and hypothermic cardiopulmonary bypass in pediatric open-heart surgery. Ann Thorac Surg. 2005;80(3):982-8. doi:10.1016/j.athoracsur.2005.03.062.

17. Poncelet AJ, van Steenberghe M, Moniotte S, Detaille T, Beauloye C, Bertrand $\mathrm{L}$, et al. Cardiac end neurological assessment of normothermia/ warm blood cardioplegia vs hypothermia/cold crystalloid cardioplegia in pediatric cardiac surgery: insight from a prospective randomized trial. Eur J Cardiothorac Surg. 2011;40(6):1384-90. doi:10.1016/j. ejcts.2011.03.047.

18. Careaga G, Salazar D, Tellez S, Sánchez O, Borrayo G, Argüero R. Clinical impact of histidine-ketoglutarate-tryptophan (HTK) cardioplegic solution on the perioperative period in open heart surgery patients. Arch Med Res. 2001;32(4):296-9. doi:10.1016/S0188-4409(01)00296-X.

19. Davidson J, Tong S, Cruz, E, Hauck A, da Cruz E, Kaufman J. Prospective validation of the vasoactive inotropic score and correlation to shortterm outcomes in neonates and infants after cardiothoracic surgery. Intensive Care Med. 2012;38(7):1184-90. doi:10.1007/s00134-012-2544-x.

20. Fannelop T, Dahle GO, Salminen PR, Moen CA, Matre K, Mongstad $A$, et al. Multidose cold oxygenated blood is superior to a single dose of Bretschineider HTK cardioplegia in the pig. Ann Thorac Surg. 2009;87(4):1205-13. doi:10.1016/j.athoracsur.2009.01.041.

21. Li XW, Lin YZ, Lin H, Huang JB, Tang XM, LuWJ, et al. Histidine-tryptophanketoglutarate solution decreases mortality and morbity in high-risk patients with severe pulmonary arterial hypertension associated with complex congenital heart disease: an 11-year experience from a single institution. Braz J Med Biol. 2016;49(6): e5208. doi:10.1590/1414431X20165208.

22. Bojan M, Peperstraete H, Lilot M, Tourneur L, Vouhé P, Pouard P. Cold histidine-ketoglutarate-tryptophan solution and repeated oxygenated warm blood cardioplegia in neonates with arterial switch operation. Ann Thorac Surg. 2013;95(4):1390-6. doi:10.1016/j.athoracsur.2012.12.025.

23. Giordano R, Arcieri L, Cantinotti M, PakV, Poli V, Maizza A, et al. Custodiol solution and cold blood cardioplegia in arterial switch operation: retrospective analysis in a single center. Thorac Cardiovasc Surg. 2016;64(1):53-8. doi:10.1055/s-0035-1566235.

24. Viana FF, Shi WY, Hayward PA, Larobina ME, Liskaser F, Matalanis G. Custodiol versus blood cardioplegia in complex operations: an Australian experience. Eur J Cardiothorac Surg. 2013;43(3):526-31. doi:10.1093/ ejcts/ezs319.

25. Oliveira MAB, Brandi AC, dos Santos CA, Botelho PHH, Cortez JLL, Godoy MF, et al. Comparison of fractal dimension and Shannon entropy in myocytes from rats treated with histidine-tryptophan-glutamate and histidine-tryptophan-cetoglutarate. Rev Bras Cir Cardiovasc. 2014;29(2):156-62. doi:10.5935/1678-9741.20140052. 